\title{
A Flexible Valuation Model Incorporating Declining Growth Rates
}

\author{
Larry C. Holland ${ }^{1}$ \\ ${ }^{1}$ College of Business, University of Arkansas Little Rock, Little Rock, AR, USA \\ Correspondence: Larry C. Holland, University of Arkasnsas Little Rock, Little Rock, AR 72204, USA.
}

Received: October 26, 2017

Accepted: November 17, 2017

Online Published: November 27, 2017

doi:10.5430/afr.v7n1p116

URL: https://doi.org/10.5430/afr.v7n1p116

\begin{abstract}
A new model is developed in this paper which demonstrates a flexible method for modeling a cash flow stream with a declining growth rate that asymptotically approaches a mature long-term growth rate. This model can be applied when the initial growth rate in cash flows is temporarily larger than the required rate of return. A simple closed form equation of the valuation model is presented along with an example to illustrate the valuation of future cash flows with a declining growth rate. A comparison is made with the valuation from multi-stage models that have constant growth segments, the H-Model, and the Ohlson-Juettner model. This highlights the difference in valuation that results from using this new model. An example is also included to illustrate how to match a decline curve to a specific forecast of future cash flows. This new declining growth model provides a flexible and practical approach for valuing equities.
\end{abstract}

Keywords: Valuation, Declining growth, Multistage model, Valuation model

\section{JEL Classification: G12, G17, C20, C65}

\section{Introduction and Literature Review}

A two-stage valuation model is routinely used by analysts to calculate the fair value of a stock. The first stage normally accommodates a high growth period for five to ten years, and the final stage assumes a long-term mature growth phase. Such a two-stage approach to valuation is necessary because the initial growth rate of cash flows is often temporarily higher than the required return, which causes a mathematical inconsistency in the constant growth model. This difficulty arises because growth rates typically decline from an initial high rate as a normal progression in the life of a business. Young businesses tend to grow at a very high initial rate because they begin at a relatively low level of product sales. As a business becomes larger, the market demand gradually becomes more satisfied and competition may occur from other firms and products. As a result, the relative growth of a business usually slows down as it gets larger. Eventually, the market becomes more saturated, which limits the ultimate growth of a business to a low mature rate of growth that reflects the increase in population or growth in the overall economy. Thus, the life cycle of a business normally includes a declining growth rate in a firm over time, which is sometimes awkward to model using valuation models with constant growth segments. A more flexible approach in this situation is to use a valuation model that incorporates a continuously declining growth rate. This approach avoids the problem of a temporarily high initial growth rate that may be larger than the required rate of return and provides flexibility in estimating future cash flows that more accurately represent the changing growth rates in a firm. In this paper, a closed form valuation model is presented which incorporates cash flows that grow at a continuously decreasing growth rate. This is a contribution to the current state of the art in equity valuation models, which predominantly includes valuation models with constant growth segments.

The literature on equity valuation models is huge, but can be summarized from material in textbooks, practitioner publications, and other selected articles. Traditional textbooks generally include discrete valuation models that incorporate some form of the Gordon (1962) constant dividend growth model (e.g. see Bodie, Kane, \& Marcus, 2017, Mayo, 2017, Hirt \& Block, 2013, and McMillan, 2011). Textbooks allow for a declining growth rate by using multistage models that step down an initially high growth rate into constant growth segments and end with a terminal value. The terminal value normally consists of a constant growth perpetuity at a low mature growth rate near the growth in the overall economy. The practitioner or trade press extends the application of constant dividend growth models by applying the constant growth models to other cash flows, such as the Free Cash Flow to the Firm (FCFF), Free Cash Flow to Equity (FCFE) and Net Operating Profit Less Adjusted Taxes (NOPLAT) (e.g., see Damodaran, 2006, 2010, 2012, Koller, Goedhart, \& Wessels, 2010, and Viebig, Poddig, \& Armaz, 2008). The CFA candidate 
body of knowledge as presented by Pinto, Henry, Robinson, and Stowe (2010) includes the Fuller and Hsia (1984) H-Model and the Residual Income Model (RIM), popularized by Feltham and Ohlson (1999). The H-Model is a valuation model that includes an approximation of a declining growth rate over a fixed number of periods. The RIM approach applies residual income rather than dividends to multistage constant growth segments and the constant growth model. Lundholm and O'Keefe (2001) and others show that the RIM approach is equivalent to the dividend growth models. Penman (2015 and 1998) also provides a review of the RIM approach in comparison to other valuation models. Finally, the Ohlson and Juettner (2005) model is an earnings capitalization valuation model that includes a declining growth component. However, the declining growth parameters in this model are not explicitly defined, and therefore this model is not very flexible in applying declining growth rates to valuation analysis.

The body of literature that compares the accuracy of various valuation models also provides evidence concerning the models being utilized by researchers. Ho, Lee, Lin, and Yu (2017) empirically compare three common valuation models: (1) A multi-stage formulation of the traditional constant growth model as demonstrated by Chen, Chen, and Wei (2011) and Hou, van Dijk, and Zhang (2012), (2) A multistage formulation of the RIM approach as demonstrated by Claus and Thomas (2001) and Gebhardt, Lee, and Swaminathan (2001), and (3) The Ohlson-Juettner (2005) earnings capitalization model. They find that the Ohlson-Juettner model provides more reliable results. Jorgensen, Lee, and Yoo (2011) also compare the RIM approach to the Ohlson-Juettner model. In contrast, their results show that the Ohlson-Juettner model underperforms the RIM approach. However, they note that their valuation estimates reflect different assumptions related to the forecast horizon and the growth rate after that horizon rather than demonstrate the accuracy of the valuation models. Courteau, Kao, and Tian (2015) compare pricing errors for stocks before and after the Sorbanes-Oxley Act using the RIM approach to valuation and a model of discounted free cash flows. In both cases, they use a multistage formulation with the constant growth formula as a terminal value. The primary difference in their two modeling approaches is the choice of future cash flows (i.e., earnings based or non-earnings based). Although the RIM approach resulted in slightly smaller pricing errors prior to the Sorbanes-Oxley Act, they find no significant difference in valuations from the two modeling approaches after the Sorbanes-Oxley Act.

To summarize the literature on valuation models, textbooks present the traditional mathematical setup of a fixed horizon forecast of valuation cash flows followed by a constant growth perpetuity as a terminal value. This valuation approach can be used with various choices for the valuation cash flows, such as dividends, free cash flow to equity, free cash flow to the firm, NOPLAT, and residual income. In each case, the discount rate should reflect the risk of the valuation cash flows being discounted. The practitioner literature adds the H-Model to this approach. And finally, more recent articles comparing the accuracy of valuation models add the Ohlson-Juettner earnings capitalization model.

The literature review also indicates that there have been no new modeling approaches to valuation since the Ohlson-Juettner model in 2005. This paper provides a contribution to the literature on equity valuation models by presenting a new approach to modeling that incorporates a feature of continuously declining growth rates. The value added in this new approach is the capability to more closely match changes that would be expected to occur over time in the life of a firm. The new model provides an explicit and flexible means of applying a changing growth rate function to valuation analysis, which is awkward and difficult to apply using currently available valuation modeling approaches.

This paper is divided into eight sections. The second section sets the stage with a basic introduction and background for the simplest multi-stage valuation model. The third section focuses on implementing the new model that incorporates a declining growth rate, and includes an example valuation problem. The next three sections compare the valuation approach of the declining growth rate model to a multi-stage model using constant growth segments, the H-Model, and the Ohlson-Juettner (2005) model. The seventh section illustrates how to match a declining growth cash flow stream to estimates of future cash flows, such as the IBES and Value Line forecasts of earnings and dividends. Finally, the last section is a summary of the paper.

\section{Background}

The present value of expected future cash flows provides a means of calculating the value of an asset. The cash flows from holding a stock are the future dividends. Therefore, the fair value of a stock can be calculated as 


$$
V_{0}=\sum_{t=1}^{\infty} \frac{D_{t}}{\left(1+R_{E}\right)^{t}}
$$

where $\quad \mathrm{V}_{0}=$ the value at time zero,

$\mathrm{D}_{\mathrm{t}}=$ the dividend at time $\mathrm{t}$, and

$\mathrm{R}_{\mathrm{E}}=$ the required rate of return for equity cash flows.

This straightforward model can be simplified by assuming a constant growth in the dividends. The constant dividend growth model was developed and popularized by Williams (1938), Gordon \& Shapiro (1956), Gordon (1962), and Gordon \& Gordon (1997). This model is

$$
V_{0}=\frac{D_{1}}{R_{E}-g_{n}}
$$

where $\quad \mathrm{g}_{\mathrm{n}}=$ a constant long-term growth rate.

There are two key restrictions in the correct application of this simple model. First, the long-term growth rate must be less than the required rate of return. Otherwise, the denominator becomes negative and the valuation is meaningless. The second restriction is that the long-term growth rate must not be significantly larger than the long-term growth in the overall economy. A larger growth rate would eventually lead to a firm that produces more than its market could sustain and that becomes very large compared to the overall economy, which again is a meaningless result. These two restrictions limit the direct application of this simple model to a very few mature companies because the short-term growth in dividends is frequently larger than the required return and the growth in the overall economy.

To overcome these two restrictions, a multistage valuation model is often utilized. A two-stage version of this model first identifies specific dividends for a finite period of time, (T). Then a terminal value is calculated using the constant growth model based on a low, long-term growth rate $\left(\mathrm{g}_{\mathrm{L}}\right)$ suitable for a mature company, as follows:

$$
V_{0}=\sum_{t=1}^{T} \frac{D_{t}}{\left(1+R_{E}\right)^{t}}+\frac{V_{T}}{\left(1+R_{E}\right)^{T}}
$$

where

$$
V_{T}=\sum_{t=1}^{\infty} \frac{D_{T+t}}{\left(1+R_{E}\right)^{t}}=\frac{D_{T+1}}{\left(R_{E}-g_{L}\right)}
$$

A straightforward version of the two-stage model in Equation 3 is to assume a constant high growth of $\mathrm{g}_{\mathrm{s}}$ from time 1 to time $\mathrm{S}$ using a constant growth annuity, followed by a low constant growth perpetuity as a terminal value beginning at time $\mathrm{S}+1$. This 2 -stage model is as follows:

$$
V_{0}=\frac{D_{1}\left[1-\left(\frac{1+g_{S}}{1+R_{E}}\right)^{S}\right]}{R_{E}-g_{S}}+\frac{D_{S+1}}{\left(R_{E}-g_{L}\right)\left(1+R_{E}\right)^{S}}
$$

The two-stage model in Equation 4 can be extended to three stages by including two fixed term growing annuities followed by a constant growth perpetuity. A 3-stage model in equation form begins with a first stage that has an initial short-term growth rate of $\mathrm{g}_{\mathrm{S}}$ from time 1 to time $\mathrm{S}$, similar to the two-stage model. The second stage steps down the growth to a middle growth rate of $\mathrm{g}_{\mathrm{M}}$ from time $\mathrm{S}+1$ to time $\mathrm{L}$. And finally, the third stage has a long-term mature growth rate of $\mathrm{g}_{\mathrm{L}}$ that begins at time $\mathrm{L}+1$ and continues thereafter. A complete equation of the 3 -stage model is as follows:

$$
V_{0}=\frac{D_{1}\left[1-\left(\frac{1+g_{S}}{1+R_{E}}\right)^{S}\right]}{R_{E}-g_{S}}+\frac{D_{S+1}\left[1-\left(\frac{1+g_{M}}{1+R_{E}}\right)^{L-S}\right]}{\left(R_{E}-g_{M}\right)\left(1+R_{E}\right)^{S}}+\frac{D_{L+1}}{\left(R_{E}-g_{L}\right)\left(1+R_{E}\right)^{L}}
$$

Using multiple fixed term constant growth annuities is somewhat cumbersome. Furthermore, the sudden change in growth rates in a step function manner usually does not reflect the way a growth rate would actually be expected to 
decline in a cash flow stream. A better fit is a valuation model that incorporates a gradually declining growth rate in cash flows over time.

\section{Modeling Cash Flows with a Declining Growth Rate}

The previous section illustrates a conventional approach to valuation using constant growth segments and the constant growth model. With a slight change in application, this approach can be modified to create a cash flow stream with a declining growth rate while retaining familiar valuation equations. The main innovation in this case is to model two cash flow streams growing at different rates and subtracting one from the other to yield a third cash flow stream that contains the desired feature - a declining growth rate. Thus, the subtraction of two cash flow streams growing at two different constant rates will yield a cash flow stream characterized by a declining growth rate. The key to the flexibility of this approach is to choose appropriately the size of these two cash flow series and their respective growth rates. First, to provide a normalized starting point of 1.00, one cash flow stream must be larger than the other by a value of 1 at time zero. Second, the two streams must grow at different rates. For the difference to approach a long-term growth rate of $g_{L}$, the larger or higher cash flow stream $(\mathrm{H})$ must grow at the rate of $g_{L}$ and the smaller or lower cash flow stream (L) at any other smaller rate, $g_{x}$. Finally, the relative size of the two cash flow streams will determine the initial growth rate for the difference series. The growth rate $g_{x}$ is arbitrary and only determines the rate of decline. A generalized set-up for the two cash flow streams is

$$
\begin{gathered}
H_{0}=\frac{g_{S}-g_{X}}{g_{L}-g_{X}} \\
L_{0}=\frac{g_{S}-g_{L}}{g_{L}-g_{X}} \\
C_{t}=C_{0}\left(H_{t}-L_{t}\right)=C_{0}\left[H_{0}\left(1+g_{L}\right)^{t}-L_{0}\left(1+g_{X}\right)^{t}\right]
\end{gathered}
$$

where $\quad \mathrm{H}_{\mathrm{t}}=$ a particular cash flow in the high cash flow stream at time $\mathrm{t}$,

$\mathrm{L}_{\mathrm{t}}=\mathrm{a}$ particular cash flow in the low cash flow stream at time $\mathrm{t}$,

$\mathrm{C}_{\mathrm{t}}=\mathrm{a}$ cash flow at time $\mathrm{t}$, beginning with $\mathrm{C}_{0}$ at time $\mathrm{t}=0$ and with a declining growth,

$\mathrm{g}_{\mathrm{S}}=$ the initial short-term growth rate of a cash flow stream from time $\mathrm{t}=0$ to $\mathrm{t}=1$,

$\mathrm{g}_{\mathrm{L}}=$ the mature long-term growth rate which is approached asymptotically, and

$\mathrm{g}_{\mathrm{X}}=$ any arbitrary growth rate generally smaller than $\mathrm{g}_{\mathrm{L}}$.

An application of Equation 8 means that if $\mathrm{H}_{0}$ grows at a constant rate of $\mathrm{g}_{\mathrm{L}}$ and $\mathrm{L}_{0}$ grows at a constant rate of $\mathrm{g}_{\mathrm{X}}$, then the difference between these two cash flow streams will be a cash flow stream with a declining growth rate. This normalized cash flow stream will have a cash flow of 1 at time zero with an initial growth rate of $g_{S}$, and over time the growth rate will decrease asymptotically to the long-term growth rate $\mathrm{g}_{\mathrm{L}}$. Then multiplying this normalized cash flow stream by the initial value of an actual cash flow will yield a matching stylized cash flow stream that exhibits a declining growth rate. An advantage of this approach is that the two normalized cash flow streams can be valued using familiar valuation formulas, such as the constant growth model of Equation 2. Then the present value of the high cash flow stream less the present value of the low cash flow stream will yield the present value of the normalized declining growth cash flow stream. The valuation of the difference between these two normalized cash flow streams can then be multiplied by the initial cash flow $\left(\mathrm{C}_{0}\right)$ of an actual cash flow stream to determine the present value of the actual declining growth cash flow stream. Therefore, the declining growth valuation model is

$$
V_{0}=C_{0}\left(\frac{H_{1}}{R_{E}-g_{L}}-\frac{L_{1}}{R_{E}-g_{X}}\right)
$$

where $\quad \mathrm{H}_{1}=\mathrm{H}_{0}\left(1+\mathrm{g}_{\mathrm{L}}\right)$

$$
\mathrm{L}_{1}=\mathrm{L}_{0}\left(1+\mathrm{g}_{\mathrm{X}}\right)
$$

Substituting for $\mathrm{H}_{0}$ and $\mathrm{L}_{0}$ from Equations 6 and 7 into Equation 9 yields a more explicit version,

$$
V_{0}=C_{0}\left(\frac{\left(\frac{g_{S}-g_{X}}{g_{L}-g_{X}}\right)\left(1+g_{L}\right)}{R_{E}-g_{L}}-\frac{\left(\frac{g_{S}-g_{L}}{g_{L}-g_{X}}\right)\left(1+g_{X}\right)}{R_{E}-g_{X}}\right)
$$


This general form for a declining growth model can be reduced to a simple formulation by assuming that the growth rate $g_{X}$ for cash flow stream $L$ is equal to zero. In this special case, there are only four parameters to specify in the model - the initial short-term growth rate $\left(\mathrm{g}_{\mathrm{S}}\right)$, the long-term growth rate $\left(\mathrm{g}_{\mathrm{L}}\right)$, the required rate of return on equity $\left(\mathrm{R}_{\mathrm{E}}\right)$, and the actual initial cash flow $\left(\mathrm{C}_{0}\right)$, which scales the normalized cash flow stream to the actual cash flow stream to be valued. Substituting $g_{X}=0$ into Equations 7, 8, and 9 provides values for $H_{0}, L_{0}$, and $C_{t}$, as follows:

$$
\begin{gathered}
H_{0}=\frac{g_{S}}{g_{L}} \\
L_{0}=\frac{g_{S}-g_{L}}{g_{L}}=\frac{g_{S}}{g_{L}}-1=H_{0}-1 \\
C_{t}=C_{0}\left(H_{t}-L_{t}\right)=C_{0}\left[H_{0}\left(1+g_{L}\right)^{t}-\left(H_{0}-1\right)\right]
\end{gathered}
$$

And finally, substituting $g_{x}=0$ into Equation 10 yields a simple formulation of the valuation model,

$$
V_{0}=C_{0}\left(\frac{H_{0}\left(1+g_{L}\right)}{R_{E}-g_{L}}-\frac{H_{0}-1}{R_{E}}\right)
$$

or

$$
V_{0}=C_{0}\left(\frac{\left(\frac{g_{S}}{g_{L}}+g_{S}\right)}{R_{E}-g_{L}}-\frac{\left(\frac{g_{S}}{g_{L}}-1\right)}{R_{E}}\right)
$$

Note that choosing $\mathrm{g}_{\mathrm{S}}=\mathrm{g}_{\mathrm{L}}$ causes Equation 14 or 15 to collapse into the constant growth formula of Equation 2,

$$
V_{0}=C_{0}\left(\frac{\left(\frac{g_{L}}{g_{L}}+g_{L}\right)}{R_{E}-g_{L}}-\frac{\left(\frac{g_{L}}{g_{L}}-1\right)}{R_{E}}\right)=\frac{C_{0}\left(1+g_{L}\right)}{R_{E}-g_{L}}
$$

Therefore, the constant growth equation can be considered a special case of the more general declining growth rate model in which the initial growth rate $\left(\mathrm{g}_{\mathrm{S}}\right)$ equals the long-term mature growth rate $\left(\mathrm{g}_{\mathrm{L}}\right)$, thus yielding the constant growth rate model.

A simple example application will illustrate the method for calculating a cash flow stream with a declining growth rate and a subsequent valuation analysis. Assume an initial cash flow of 1.00 that increases at an initial growth rate of $24 \%$ declining asymptotically to a long-term growth rate of $2 \%$, and a required rate of return of $10 \%$. Evaluating Equations 11 and 12 and the declining growth valuation model in Equation 15 yields a fair value of 43.00 at time zero, as follows:

$$
\begin{gathered}
H_{0}=\frac{g_{S}}{g_{L}}=\frac{24 \%}{2 \%}=12 \\
C_{t}=C_{0}\left(H_{t}-L_{t}\right)=C_{0}\left[H_{0}\left(1+g_{L}\right)^{t}-\left(H_{0}-1\right)\right]=1.00\left[12(1.02)^{t}-11\right] \\
V_{0}=C_{0}\left(\frac{H_{0}\left(1+g_{L}\right)}{R_{E}-g_{L}}-\frac{H_{0}-1}{R_{E}}\right)=1.00\left(\frac{12(1.02)}{0.10-0.02}-\frac{12-1}{.10}\right)=43.00
\end{gathered}
$$

Table 1 shows the results for calculating the first 10 years of the raw cash flows and their present values. Figure 1 further illustrates how the growth rate declines over a 100-year period in the future. 
Table 1. Calculating Cash Flows with a Declining Growth Rate (First 10 Years Shown)

\begin{tabular}{cccccccc}
\hline Year & $\mathrm{H}_{\mathrm{t}}$ & \multicolumn{1}{c}{$\mathrm{L}_{\mathrm{t}}$} & $\mathrm{Ht}-\mathrm{Lt}$ & $\mathrm{g}$ & $\mathrm{PV}\left(\mathrm{H}_{\mathrm{t}}\right)$ & $\mathrm{PV}\left(\mathrm{L}_{\mathrm{t}}\right)$ & $\mathrm{PV}\left(\mathrm{H}_{\mathrm{t}}-\mathrm{L}_{\mathrm{t}}\right)$ \\
\hline 0 & 12.00 & 11.00 & 1.00 & & & & \\
1 & 12.24 & 11.00 & 1.24 & $24.00 \%$ & 11.13 & 10.00 & 1.13 \\
2 & 12.48 & 11.00 & 1.48 & $19.74 \%$ & 10.32 & 9.09 & 1.23 \\
3 & 12.73 & 11.00 & 1.73 & $16.82 \%$ & 9.57 & 8.26 & 1.30 \\
4 & 12.99 & 11.00 & 1.99 & $14.68 \%$ & 8.87 & 7.51 & 1.36 \\
5 & 13.25 & 11.00 & 2.25 & $13.06 \%$ & 8.23 & 6.83 & 1.40 \\
6 & 13.51 & 11.00 & 2.51 & $11.78 \%$ & 7.63 & 6.21 & 1.42 \\
7 & 13.78 & 11.00 & 2.78 & $10.75 \%$ & 7.07 & 5.64 & 1.43 \\
8 & 14.06 & 11.00 & 3.06 & $9.90 \%$ & 6.56 & 5.13 & 1.43 \\
9 & 14.34 & 11.00 & 3.34 & $9.19 \%$ & 6.08 & 4.67 & 1.42 \\
10 & 14.63 & 11.00 & 3.63 & $8.58 \%$ & 5.64 & 4.24 & 1.40 \\
\hline
\end{tabular}

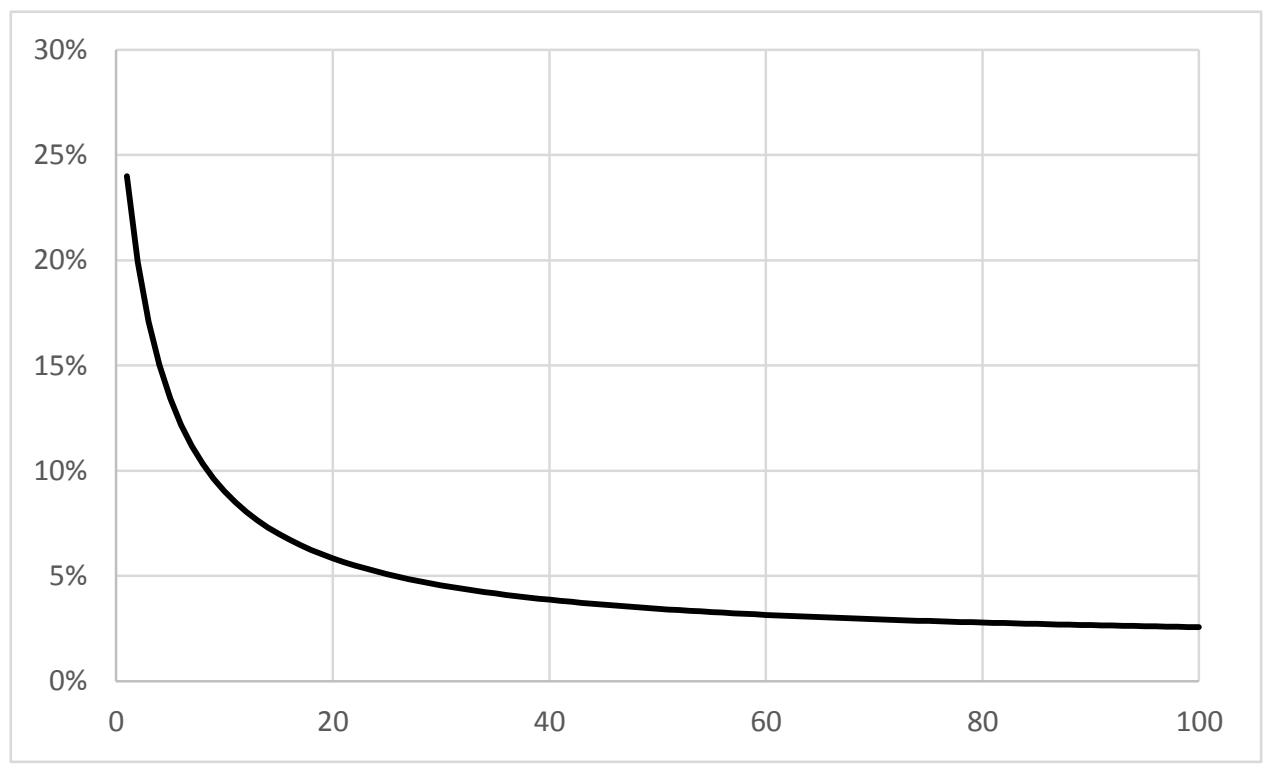

Figure 1. 24\% Growth Rate Declining Asymptotically Towards a 2\% Long-Term Growth Rate

When a discount rate reflecting a required rate of return of $10 \%$ is applied to the valuation of a cash flow stream with a declining growth rate, a stream of present value cash flows is the result. This is illustrated in Figure 2. Note that the present values are increasing (decreasing) when the growth rate is above (below) the required rate of return. Also, when the initial growth rate is above the required rate of return, as the growth rate declines, the series reaches a maximum when the growth rate equals the required rate of return. Figure 2 also shows that with a required rate of return of $10 \%$, the present values approach zero within a 100-year period. 


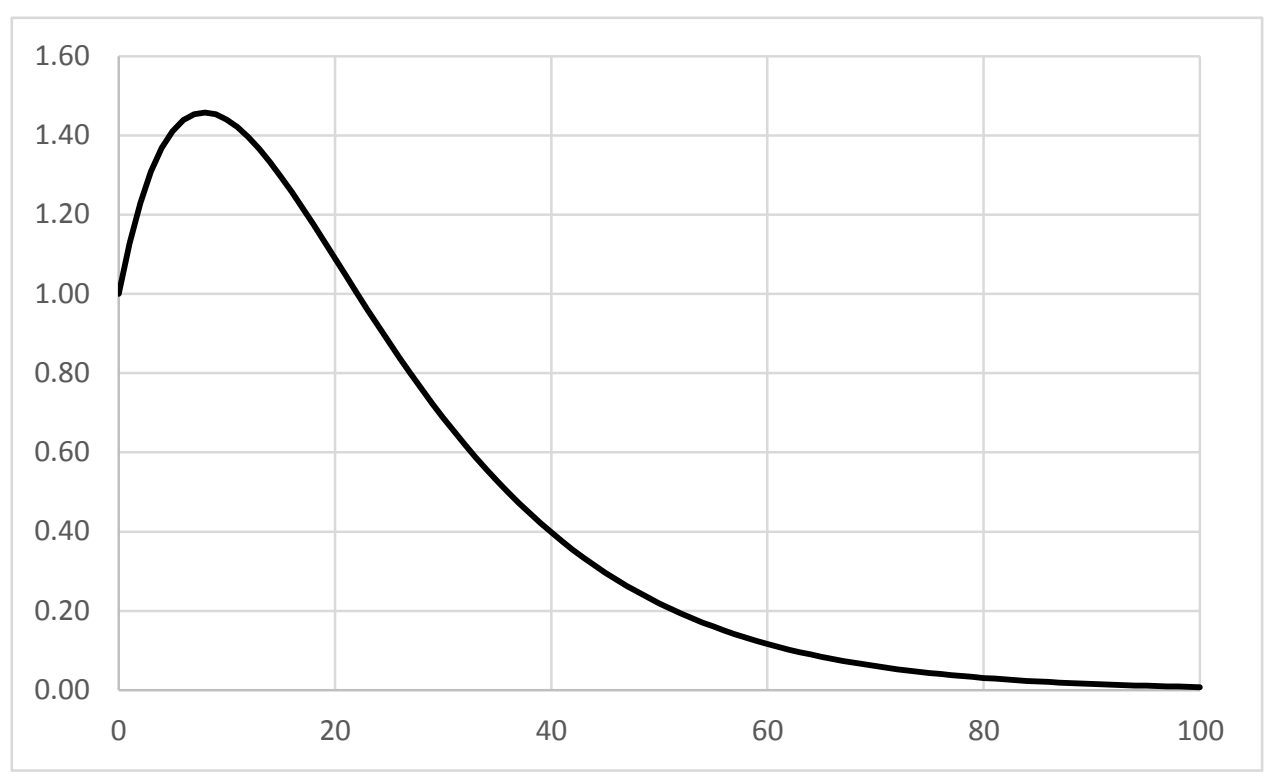

Figure 2. Present Value Cash Flows Over 100 Years as Growth Declines to 2\% (Required Return $=10 \%$ )

\section{Comparison with Multi-Stage Constant Growth Models}

As shown earlier, a commonly used method for estimating a cash flow stream with a declining growth rate is a multi-stage model with various constant growth rate segments, such as the 2-stage model defined in Equations 3 and 4, or a 3-stage model as defined in Equation 5. As a point of comparison, the 3-stage constant growth model can be compared to the declining growth model by approximating the declining growth in three segments. For example, a cash flow stream with an initial growth of $24 \%$ and decreasing asymptotically to $2 \%$ could be approximated by constant growth segments of $18 \%$ for 5 years, $8 \%$ for 15 years, and $2 \%$ thereafter (see Figure 3 ).

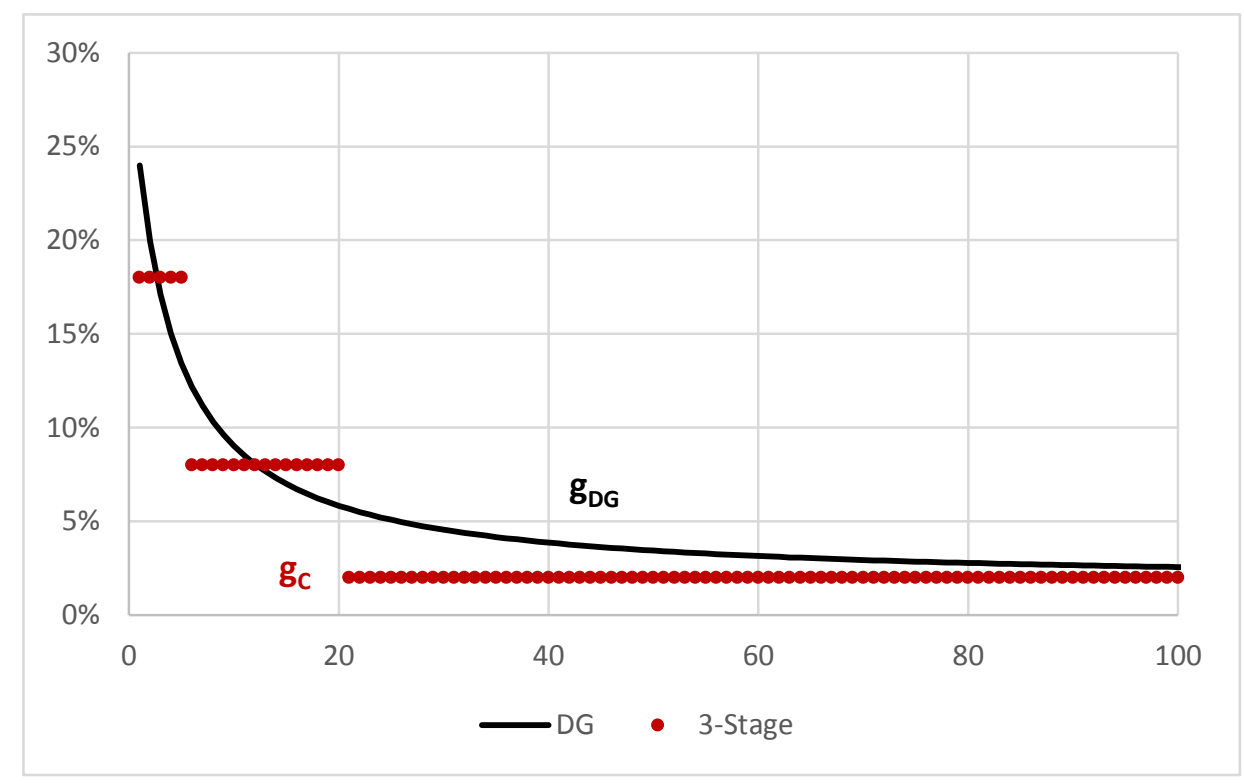

Figure 3. A Comparison of Continuous Declining Growth and 3-Stage Constant Growth

Given an initial dividend of 1.00 at time zero, this choice of constant growth segments will yield approximately the same dividend in 20 years as the declining growth model. Figure 4 shows the results of the present values over a 100 -year period for these two approaches using a constant required return of $10 \%$ per year. The area under each curve represents the sum of all present values for each approach (i.e., the current fair value). 


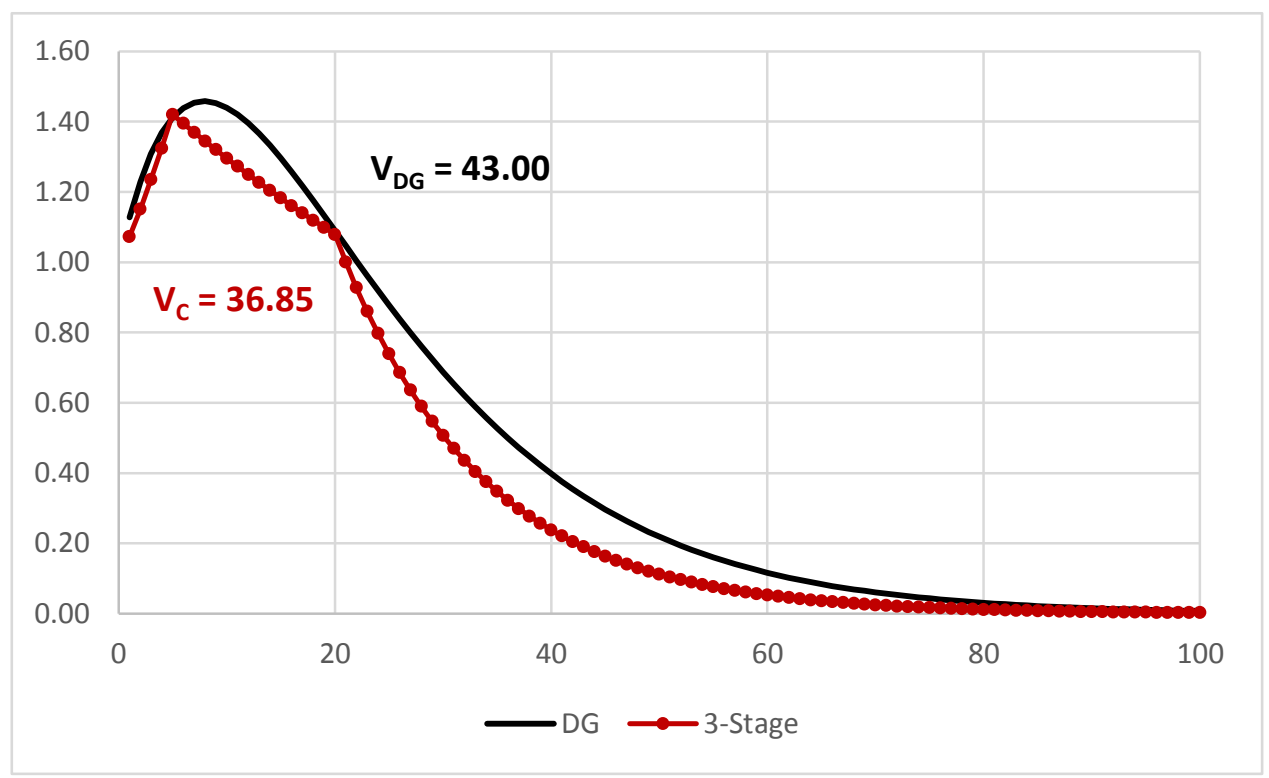

Figure 4. Present Value Cash Flows - Declining Growth vs. 3-Stage Constant

Applying Equation 5, the total valuation for the 3-stage approach (i.e., the present value of all future cash flows) is 36.85. This is a lower estimate of the fair value than the valuation of 43.00 using the declining growth model.

There are several problems with using a constant growth segmented approach in valuation analysis. First, growth rates do not always remain constant for an extended period and then suddenly jump downwards. Under the life cycle theory, the growth rate in a firm gradually decreases over time, and then stabilizes at a low growth rate (i.e., 2-3\% per year) throughout maturity. A second problem is that constant growth segments will result in a series of convex curves for the present values, which curve upward when the constant growth is above the required return, and then curve exponentially downward when the constant growth rate is below the required rate of return. And finally, when the terminal value is assumed to be a constant growth perpetuity at maturity, the present value cash flow stream will decrease asymptotically towards zero in a convex curve. In contrast, the present value series of cash flows with a continuously declining growth rate is a concave function when the initial growth rate is higher than the required rate of return, and reaches a peak at the point that the growth rate equals the required return. Then the present values decline, gradually changing from a concave curve to a convex curve as they proceed towards zero and the growth rate continues to decrease to the long-term growth rate through maturity. The convex present value functions of constant growth segments are thus subject to a somewhat lower total valuation than the present values from the continuous declining growth model, which have an initial concave function that gradually turns convex.

\section{Comparison with the H-Model}

The H-Model attempts to compensate for a declining growth rate, but still with a convex function of the present value cash flow stream. The H-Model is

$$
V_{0}=\frac{D_{0}\left(1+g_{L}\right)}{R_{E}-g_{L}}+\frac{D_{0}\left(\frac{n}{2}\right)\left(g_{S}-g_{L}\right)}{R_{E}-g_{L}}
$$

where $\quad n=$ period from time zero in which the growth declines from $g_{S}$ to $g_{L}$, and

$\mathrm{R}_{\mathrm{E}}=$ the required rate of return on equity.

Note that both terms are divided by a common denominator. The numerator of the second term adds to the beginning dividend at time 1 (i.e., $\mathrm{D}_{1}$ ) to compensate for the additional value during the decline in growth rates. This enhanced value is then treated as a constant growth perpetuity with a constant required rate of return. In this way, the H-Model incorporates an estimate of a declining growth stage as well as a final mature stage. Repeating the previous example 
problem, a linear decline from $24 \%$ to $2 \%$ in the H-Model can be assumed over a 20 -year period to compare to the declining growth model, as illustrated in Figure 5.

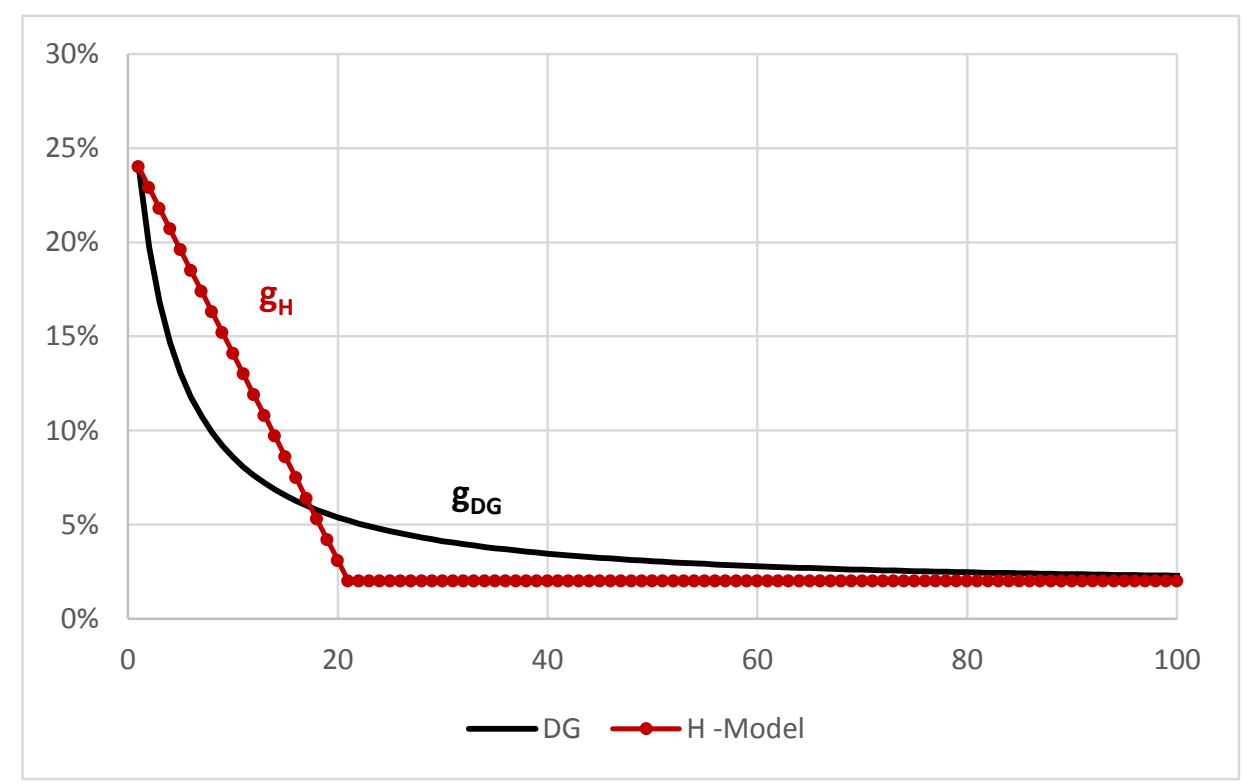

Figure 5. A Comparison of Continuous Declining Growth and H-Model

Applying the H-Model to valuation yields

$$
V_{0}=\frac{1.00(1.02)}{.10-.02}+\frac{\left(\frac{20}{2}\right)(.24-.02)}{.10-.02}=12.75+27.50=40.25
$$

The calculated value of 40.25 in the H-Model is slightly lower than the declining growth model result of 43.00. However, the underlying path of the present values for the H-Model valuation does not match the actual higher growth phase when the growth rate is above the required rate of return on equity. Figure 6 shows the present value cash flow pattern of the example valuation for the H-Model as compared to the declining growth model. Note that the H-Model does not include a maximum point when the growth rate equals the required rate of return.

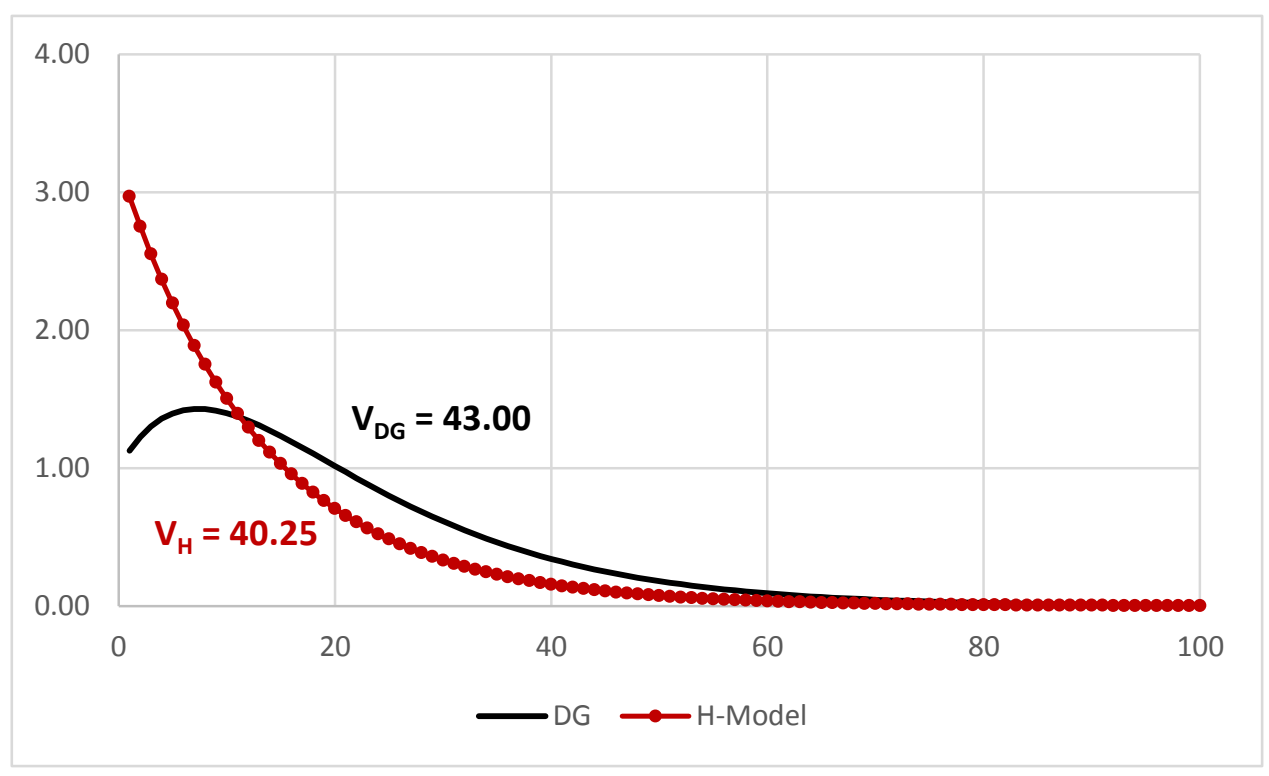

Figure 6. Present Value Cash Flows - Declining Growth Model vs. H-Model 


\section{Comparison with the Ohlson-Juettner Model}

The Ohlson-Juettner (OJ) Model is an earnings capitalization valuation model which includes abnormal earnings and a built-in function to compensate for the effect on growth from the payout of dividends. It also contains a feature that includes a declining growth rate cash flow stream, although this feature is not clearly explicit. The OJ Model is

$$
\begin{gathered}
V_{0}=\frac{E_{1}}{R}+\frac{Z_{1}}{R-g_{L}} \\
Z_{t}=\frac{1}{R}\left[E_{t+1}+R D_{t}-(1+R) E_{t}\right] \\
Z_{t+1}=\left(1+g_{L}\right) Z_{t}
\end{gathered}
$$

where $\quad Z_{\mathrm{t}}=$ the capitalized abnormal earnings factor for any year $t$,

$\mathrm{E}_{1}=$ the forward earnings over the next year,

$\mathrm{E}_{2}=$ the forward earnings two years ahead, and

$\mathrm{D}_{1}=$ the dividend to be paid one year from now.

In this case, earnings rather than dividends are expected to grow initially at $24 \%$ per year and decline asymptotically to a long-term growth of $2 \%$ per year. The declining growth rates within the OJ model are not readily apparent in the valuation equation, but are a function of the choice of $Z_{1}$ and the retention rate (b). It can be shown that the growth rates for net income will be $\mathrm{g}_{\mathrm{S}}=24 \%$ and $\mathrm{g}_{\mathrm{L}}=2 \%$ when the values of $\mathrm{Z}_{1}$ and $\mathrm{b}$ are chosen as

$$
Z_{1}=\frac{g_{S}-g_{L}}{R}=\frac{.24-.02}{0.10}=2.2 \quad \text { and } \quad b=\frac{g_{L}}{R}=\frac{.02}{0.10}=0.2
$$

With these parameters, the valuation of the OJ model is

$$
V_{0}=\frac{E_{1}}{R}+\frac{Z_{1}}{R-g_{L}} V_{0}=\frac{1.24}{0.10}+\frac{2.2}{0.10-0.02}=12.4+27.50=39.90
$$

The valuation of the OJ model is based on earnings capitalization and therefore is not directly comparable to the present value of a dividend cash flow stream. The valuation of the OJ model is not sensitive to the choice of retention ratio or pattern of dividend payouts. However, adjusting the OJ model to result in a specific level of dividends and declining growth rates does require specific values for earnings and the retention ratio. For example, the initial earnings of 1.00 with a retention ratio of 0.2 yields an initial dividend of 0.80 . By increasing the initial earnings to 1.25 , the initial dividends will be $0.8(1.25)=1.00$. With a constant retention ratio of 0.20 , the initial dividend of 1.00 will grow initially at $24 \%$, declining asymptotically to $2 \%$. The $25 \%$ increase in earnings will therefore also increase the model valuation in Equation 25 by $25 \%$ from 39.90 to 49.88 . This modified result can now be compared directly to the results from the declining growth valuation of 43.00 . The somewhat higher valuation of 49.88 for the OJ model is due to a slower decline rate built into the OJ model as compared to the simple declining growth model. Figure 7 illustrates that the declining growth rates are slightly higher for the OJ model. Figure 8 shows that the dividend present value stream for the OJ Model is also slightly higher than the declining growth model, which explains the slightly higher valuation. However, this example also demonstrates that the OJ Model is not straightforward to apply when modeling a declining growth function. 


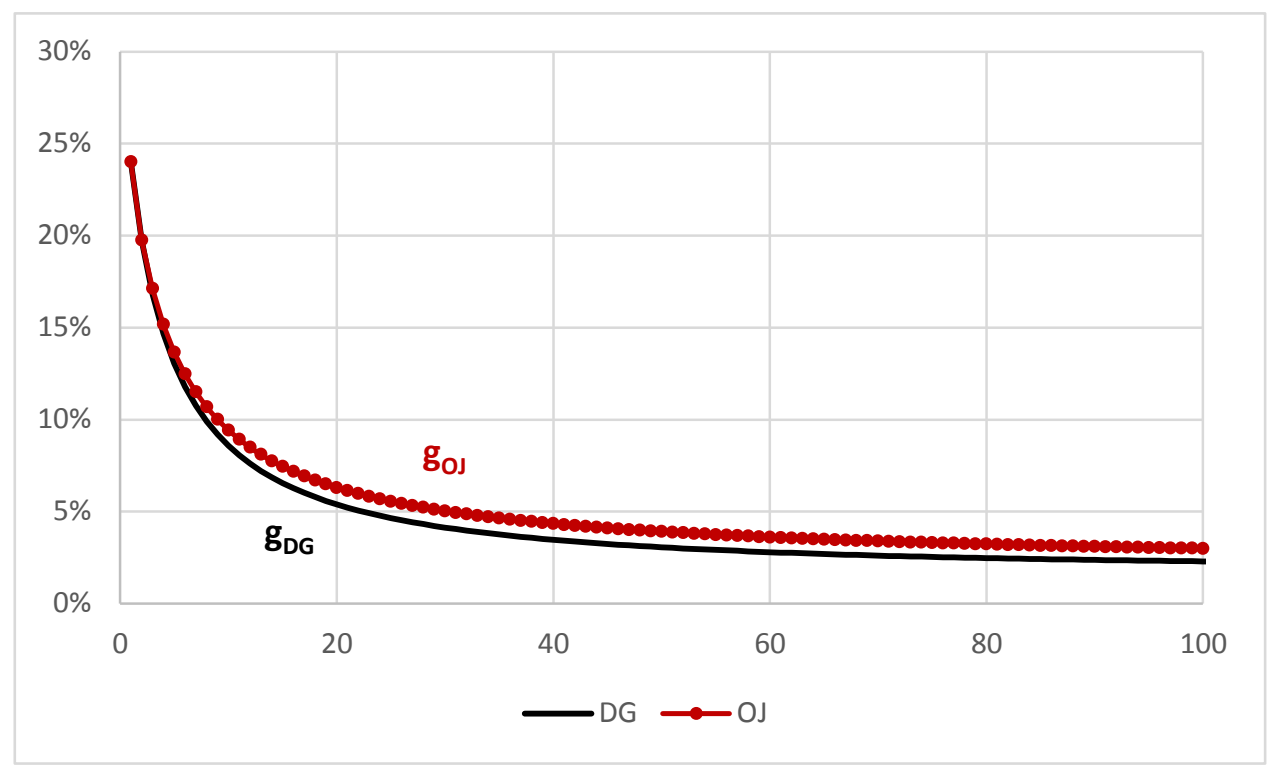

Figure 7. A Comparison of Continuous Declining Growth and the OJ Model)

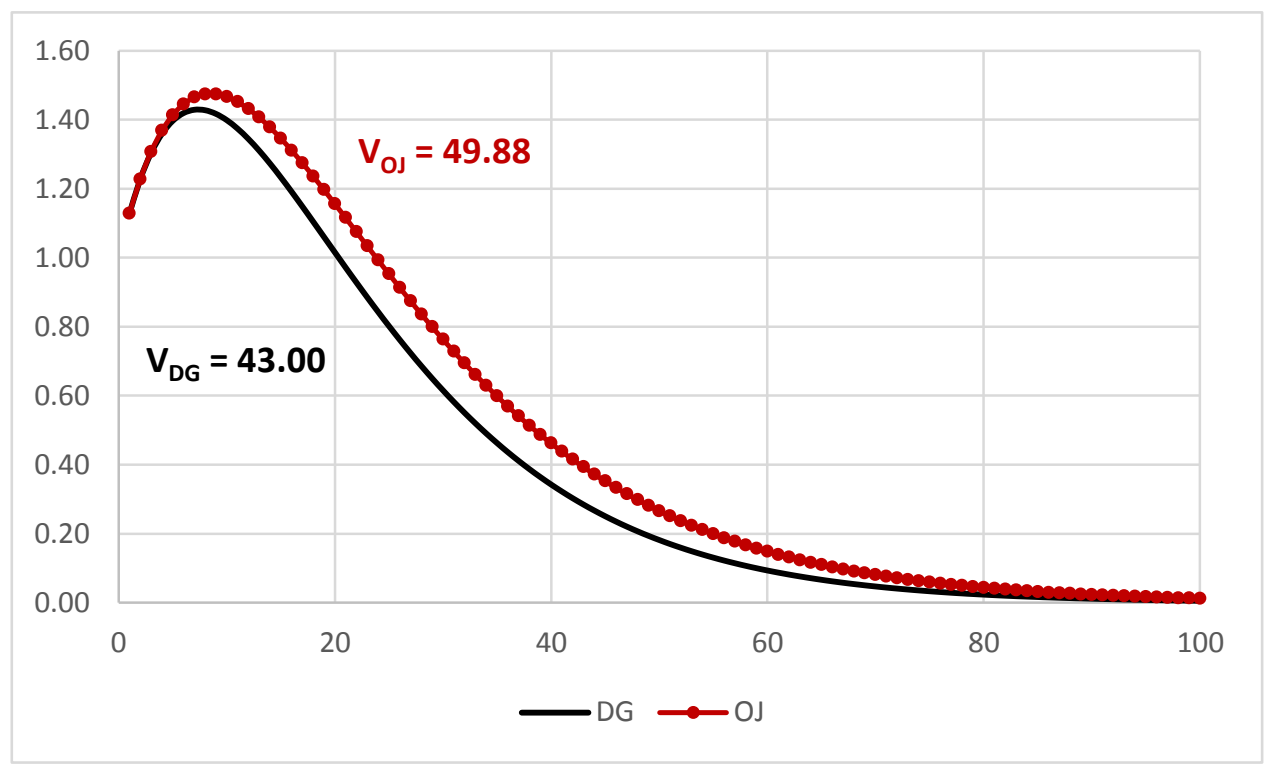

Figure 8. Present Value Cash Flows - Declining Growth Model vs. the OJ Model

\section{Matching a Forecasted Cash Flow}

In some cases, an analyst has access to or can develop a short-term forecast of future dividends or earnings. A nice feature of the declining growth model is the ability to easily match a specific decline curve to a forecasted cash flow. For example, IBES, Value Line, and other sources typically provide a forecast of earnings and/or dividends three to five years into the future. A formula for matching a future cash flow can easily be derived from the definition of the simplified form of the model. Substituting Equations 11 and 12 into Equation 13 and solving for $C_{t} / C_{0}$ yields

$$
\frac{C_{t}}{C_{0}}=\left[\frac{g_{S}}{g_{L}}\left(1+g_{L}\right)^{t}-\left(\frac{g_{S}}{g_{L}}-1\right)\right]=\frac{g_{S}}{g_{L}}\left[\left(1+g_{L}\right)^{t}-1\right]+1
$$


Solving for $g_{s}$ yields

$$
g_{S}=\left(\frac{C_{t}}{C_{0}}-1\right) \frac{g_{L}}{\left(1+g_{L}\right)^{t}-1}
$$

Equation 26 identifies the initial growth rate that will create a cash flow stream from Equation 13 that begins with a cash flow of $\mathrm{C}_{0}$, passes through the forecasted value of $\mathrm{C}_{\mathrm{t}}$, and then the growth rate continues to decline asymptotically to the long-term growth rate of $\mathrm{g}_{\mathrm{L}}$. The ease and simplicity of using the declining growth model can be illustrated with another example calculation. Suppose at the beginning of the year an analyst estimates a dividend of 3.56 for next year, 4.45 in two years, and a dividend of 5.45 for 5 years in the future (e.g., from a Value Line forecast). The analyst also estimates a required return on equity of $7.25 \%$ and a long-term growth rate of $2 \%$ per year. The estimated dividends for year 2 through 5 and beyond can be matched with Equation 26, as follows:

$$
g_{S}=\left(\frac{C_{t}}{C_{0}}-1\right) \frac{g_{L}}{\left(1+g_{L}\right)^{t}-1}=\left(\frac{5.45}{4.45}-1\right) \frac{.02}{(1.02)^{3}-1}=7.3428 \%
$$

Using this calculated initial growth rate of $7.3428 \%$, a matching cash flow stream can be developed by applying Equations 11 and 12 in year 2 of the forecast, as follows:

$$
\begin{gathered}
H_{2}=\frac{g_{S}}{g_{L}}=\frac{7.3428 \%}{2 \%}=3.6714 \\
C_{t}=C_{2}\left[H_{2}\left(1+g_{L}\right)^{t}-\left(H_{2}-1\right)\right]=4.45\left[3.6714(1.02)^{t}-2.6714\right]
\end{gathered}
$$

Table 2 shows the results of this cash flow matching for the first 10 years of the forecast.

Table 2. Matching Cash Flows Beginning in Year 2 with a Declining Growth Rate (First 10 Years Shown)

\begin{tabular}{rccccc}
\hline Year & $\mathrm{H}_{\mathrm{t}}$ & $\mathrm{L}_{\mathrm{t}}$ & $\mathrm{H}_{\mathrm{t}}-\mathrm{L}_{\mathrm{t}}$ & $\mathrm{C}_{\mathrm{t}}$ & $\mathrm{g}$ \\
\hline 1 & & & & 3.5600 & \\
2 & 3.6714 & 2.6714 & 1.0000 & 4.4500 & \\
3 & 3.7448 & 2.6714 & 1.0734 & 4.7768 & $7.3428 \%$ \\
4 & 3.8197 & 2.6714 & 1.1483 & 5.1100 & $6.9773 \%$ \\
5 & 3.8961 & 2.6714 & 1.2247 & 5.4500 & $6.6527 \%$ \\
6 & 3.9740 & 2.6714 & 1.3026 & 5.7968 & $6.3625 \%$ \\
7 & 4.0535 & 2.6714 & 1.3821 & 6.1504 & $6.1015 \%$ \\
8 & 4.1346 & 2.6714 & 1.4632 & 6.5112 & $5.8657 \%$ \\
9 & 4.2173 & 2.6714 & 1.5459 & 6.8792 & $5.6515 \%$ \\
10 & 4.3016 & 2.6714 & 1.6302 & 7.2545 & $5.4561 \%$ \\
\hline
\end{tabular}

Note that the second-year cash flow of 4.45 three years later matches the 5-year cash flow of 5.45 with a continual decrease in the growth rate as it declines asymptotically towards the long-term growth rate of $2 \%$ per year. Given this data, the valuation model in Equation 15 can be applied as a terminal value at the end of year 2, as follows: 


$$
\begin{gathered}
V_{t}=C_{t}\left(\frac{\left(\frac{g_{S}}{g_{L}}+g_{S}\right)}{R_{E}-g_{L}}-\frac{\left(\frac{g_{S}}{g_{L}}-1\right)}{R_{E}}\right) \\
V_{2}=4.45\left(\frac{\left(\frac{.073428}{.02}+.073428\right)}{.0725-.02}-\frac{\left(\frac{.073428}{.02}-1\right)}{.0725}\right)=153.45
\end{gathered}
$$

A fair value of this stock as of the beginning of the current year would be the present value of the first two dividends and a terminal value at the end of year 2, as follows:

$$
\begin{gathered}
V_{0}=\frac{D_{1}}{(1+R)}+\frac{D_{2}}{(1+R)^{2}}+\frac{V_{2}}{(1+R)^{2}} \\
V_{0}=\frac{3.56}{(1.0725)}+\frac{4.45}{(1.0725)^{2}}+\frac{153.45}{(1.0725)^{2}} \\
V_{0}=3.319+3.869+133.405=140.59
\end{gathered}
$$

\section{Summary}

A valuation model with a declining growth rate is developed in this paper which provides the flexibility to match more closely the cash flows for a firm that exhibits a typical life cycle pattern with a declining growth rate. This model can easily incorporate a high initial growth rate which is above the required rate of return and which is expected to decline to a lower mature growth rate over time. An example problem is illustrated to show the differences in valuation an analyst might expect using this declining growth model as compared to a valuation model with constant growth segments, the H-Model, and the Ohslon-Juettner model. Finally, the flexibility of this new declining growth model is shown by demonstrating a method for matching an estimated future cash flow with a stylized declining growth cash flow stream that declines to a long-term mature growth rate. The valuation examples illustrate that this new declining growth model provides a flexible and practical method for the valuation of equities. Future research will be necessary to empirically test the accuracy of this new model compared to existing equity valuation models.

\section{References}

Bodie, Z., Kane, A., \& Marcus, A. (2017). Essentials of Investments (10 ${ }^{\text {th }}$ Ed.). New York: McGraw Hill.

Chen, K. C. W., Z. Chen, \& K. C. J. Wei. (2011). Agency costs of free cash flow and the effect of shareholder rights on the implied cost of equity capital. Journal of Financial and Quantitative Analysis, 46 (1), $171-207$. https://doi.org/10.1017/S0022109010000591

Claus J., \& J. Thomas. (2001). Equity premia as low as three percent? Evidence from analysts' earnings forecasts for domestic and international stock markets. Journal of Finance, 56, 1629-1666. https://doi.org/10.1111/0022-1082.00384

Courteau, Luci, Jennifer Kao, \& Yao Tian. (2015). Does accrual management impair the performance of earnings-based valuation models? Journal of Business Finance \& Accounting 42(1), 101-137. https://doi.org/10.1111/jbfa.12101

Damodaran, Aswath. (2006). Damodaran on Valuation ( ${ }^{\text {nd }}$ Ed.). Hoboken, N.J.: John Wiley and Sons. https://doi.org/10.1002/9781119201786

Damodaran, Aswath. (2010). The Dark Side of Valuation (2 ${ }^{\text {nd }}$ Ed.). Pearson Education, Inc. Upper Saddle River, New Jersey 07458. https://doi.org/10.5860/choice.47-5115

Damodaran, Aswath. (2012). Investment Valuation (University Edition) ( ${ }^{\text {rd }}$ Ed.). Hoboken, N.J.: John Wiley and Sons. 
Feltham, James \& James Ohlson. (1999). Residual earnings valuation with risk and stochastic interest rates. Accounting Review, 74 (April), 165-183. https://doi.org/10.2308/accr.1999.74.2.165

Fuller, Russell J. \& Chi-Cheng Hsia. (1984). A simplified common stock valuation model. Financial Analysts Journal (Sept-Oct), 49-56. https://doi.org/10.2469/faj.v40.n5.49

Gebhardt, W., C. M. Lee, \& B. Swaminathan. (2001). Toward an implied cost of capital. Journal of Accounting Research, 39, 135-176. https://doi.org/10.1111/1475-679X.00007

Gordon, M. (1962). The Investment, Financing, and Valuation of the Corporation. IL: Richard D. Irwin.

Gordon, M. \& Shapiro, E. (1956). Capital equipment analysis: The required rate of profit. Management Science, 3(1), 102-110. https://doi.org/10.1287/mnsc.3.1.102

Gordon, J. \& M. Gordon. (1997). The finite horizon expected return model. Financial Analysts Journal, 53, 52-61. https://doi.org/10.2469/faj.v53.n3.2084

Hirt, Geoffrey \& Stanley Block. (2012). Fundamentals of Investment Management $\left(10^{\text {th }}\right.$ Ed.). NY: McGraw-Hill/Irwin.

Ho, Kung-Cheung, Shih-Cheng Lee, Chien-Ting Lin, \& Min-The Yu. (2017). A comparative analysis of accounting-based valuation models. Journal of Accounting, Auditing \& Finance, 32(4), 561-575. https://doi.org/10.1177/0148558X15623043

Hou, K., M. van Dijk, \& Y. Zhang. (2012). The implied cost of capital: A new approach. Journal of Accounting \& Economics, 53, 504-526. https://doi.org/10.1016/j.jacceco.2011.12.001

Jorgensen, B. N., Y. G. Lee, \& Y. K. Yoo. (2011). The valuation accuracy of equity value estimates inferred from conventional empirical implementations of the abnormal earnings growth model: US evidence. Journal of Business Finance \& Accounting, 38, 446-471. https://doi.org/10.1111/j.1468-5957.2011.02241.x

Koller, T., Goedhart, M. \& Wessels, D. (2010). Valuation: Measuring and Managing the Value of Companies, $\left(5^{\text {th }}\right.$ University Ed.) Hoboken, NJ: John Wiley and Sons.

Lundholm, Russell \& Terry O'Keefe. (2001). Reconciling value estimates from the discounted cash flow model and the residual income model. Contemporary Accounting Research, 18(2), 311-335. https://doi.org/10.1092/w13b-k4bt-455n-ttr2

Mayo, Herbert. (2017). Investments: An Introduction (12 ${ }^{\text {th }}$ Ed.). Boston: Cengage Learning.

McMillan, M. (2011). Investments: Principles of Portfolio and Equity Analysis. Hoboken, NJ: John Wiley and Sons.

Ohlson, J. \& B. Juettner-Nauroth. (2005). Expected EPS and EPS growth as determinants of value. Review of Accounting Studies 10, 349-365. https://doi.org/10.1007/s11142-005-1535-3

Penman, S. (2015). Valuation models: An issue of accounting theory. In S. Jones (Ed.), Routledge Companion to Financial Accounting Theory (pp. 236-253). New York, NY: Routledge.

Penman, S. (1998). A synthesis of equity valuation techniques and terminal value calculation for the dividend discount model. Review of Accounting Studies, 2, 303-323. https://doi.org/10.1023/A:1023688704798

Pinto, J., Henry, E., Robinson, T. \& Stowe, J. (2010). Equity Asset Valuation, (2 ${ }^{\text {nd }}$ Ed.). Hoboken, NJ: John Wiley and Sons.

Viebig, Jan, Thorsten Poddig, \& Armin Varmaz. (2008). Equity Valuation: Models from Leading Investment Banks. Hoboken, NJ: John Wiley and Sons. https://doi.org/10.1002/9781119208754

Williams, J. B. (1938). The Theory of Investment Value. 1997 reprint, Fraser Publishing. Cambridge: Harvard University Press. 